\title{
Förtryck av ett minoritetsfolk. Postkoloniala aspekter på indianböcker för barn och unga
}

Stig Ericson (1929-1986) tillhör den svenska litteraturens nydanare vad gäller kategorin indianböcker. Men vilken bild av Nordamerikas ursprungsbefolkning presenteras i hans böcker? Yvonne Pålsson gör en jämförelse mellan Indianupproret från 1963 och Lilla Vargen och de talande tecknen från 1985, ur postkolonial synvinkel.

De västerländska imperiernas uppkomst och allt som följde i deras spår i form av slaveri, tvångsförflyttningar, folkvandringar och etnisk och kulturell diskriminering är utgångspunkt för den postkoloniala teorin. I The Empire Writes Back menar författarna att termen postkolonial täcker kultur som påverkats av den imperialistiska processen från det ögonblick kolonisationen var ett faktum till dags dato (Ashcroft 2002). Postkolonial teori är sålunda ett både vitt och heterogent begrepp. Grundläggande är att den länkar ihop kolonialmakternas påverkan med motståndet från de tidigare koloniserade samhällena, medan den lokala förankringen visar variationerna. De stora frågorna som diskuteras i litteratur om postkolonial teori behandlar historia, plats, språk och identitet.

\section{Postkolonial teori i relation till barn- och ungdomslitteratur}

Hur är det då med barn och ungdomar? Är inte de utsatta för en förmyndarattityd? Deras litteratur både skrivs och kritiseras i regel av vuxna. Detta är en återkommande fråga i texter om postkolonial teori och barnlitteratur. En jämförelse mellan Edward Saids tankar om västvärldens förtryck av andra kulturer med vuxenvärldens syn på barn- och ungdomskultur visar svårigheterna att undvika rollen som kolonisatör (Nodelman 1992). Med detta synsätt skulle emellertid all barn- och ungdomslitteratur kunna definieras som kolonial och en analys ur postkolonialt perspektiv bli verkningslös. Dilemmat är i grunden olösligt, men barn- och ungdomsboksförfattare bör vara medvetna om sin imperialistiska roll. En liknande diskussion förs i inledningen till det nummer av tidskriften Ariel som helt ägnas 
åt postkolonialism i relation till barn- och ungdomslitteratur (McGillis 1997). Som medvetna vuxna kan vi lyfta fram böcker från olika kulturer och visa att dessa berättelser är lika värdefulla och inspirerande som de förhärskande västerländska.

\section{Postkolonial kritik}

Den postkoloniala teorin öppnar även för möjligheten att läsa tidigare litterära verk på ett nytt sätt. Det gäller att bli medveten om att marginalisering på grund av ras, kön, geografiskt och socialt avstånd oftast är en konstruktion utan reell grund. "Postcolonial reading uncovers the constructedness of cultural identity." (McGillis 1997, 12). Som exempel kan nämnas en postkolonial läsning av Frances Hodgson Burnetts bok A Little Princess. Saras prinsesstitel kan ses som en representation av det engelska imperiet, medan Ram Dass skildras som stereotypen för den indiske tjänaren (Reimer 2000).

\section{Postkolonial teori och Nordamerikas indianer}

Kolonisation som ledde till invasioner av nybyggare kan ses som en variant inom den postkoloniala teorin. Som underlag för sina studier ger Clare Bradford följande definition: "I define settler societies as those where colonization took the form of invasion by a European power, where colonizers (settlers) exercised racial domination over the autochthonous inhabitants of the lands they invaded, and where Indigenous peoples continue to seek recognition, compensation, and self-determination." (Bradford 2007, 4). Bland minoritetsbefolkningarna är nog Nordamerikas indianer den folkgrupp som utsatts för de mest stereotypa skildringarna i barn- och ungdomslitteraturen. Benämningen "indianer" är kontroversiell och redan den ett uttryck för den koloniala strukturen. I förordet till Through indian eyes, en samlingsvolym med artiklar, recensioner och en vägledning $i$ att se fördomar i barn- och ungdomsböcker om indianer, diskuteras namnfrågan: "None of the terms "Native American", "Indian", or "American Indian" is more acceptable. All of these terms are, to say the least, inaccurate, since "Indians" were namned for a geographical mistake almost five hundred years ago." Varje stam eller nation har sitt eget namn och vill bli omnämnd med detta. De som inte tillhör urinvånarna är dock sällan insatta i namnfrågan och då är det mer praktiskt att använda en samlande benämning. Så sker också i Through indian eyes och många andra texter om Nordamerikas ursprungsbefolkning. Av samma skäl använder jag här oftast ordet "indianer". Annika Holmbom undersöker i sin uppsats "I didn't even know what an Indian was": resisting aboriginal stereotypes in children's picture books 
hur indianska författare från Canada, i ett antal bilderböcker, skriver i dialog med eller motstånd mot icke-indianska författare. Hon kan då visa hur den postkoloniala diskursen kan användas för att urskilja vilka indianböcker för barn som är autentiska vad gäller synen på befolkning, land, historia, språk, sociala relationer och självkänsla. I en studie av ungdomsböcker med indianska motiv konstaterar Paulette F Molin att den europeiska kolonisationens verkningar fortfarande sätter sina spår på ursprungsbefolkningarnas liv och att indianska författare ständigt bearbetar förlusten av land, kultur, identitet och självkänsla (Molin 2005).

\section{Postkoloniala författare}

En upprepad fråga vad gäller den postkoloniala litteraturens avgränsning är författarens bakgrund. När det gäller barn- och ungdomslitteratur är kravet på skildringen av huvudpersonerna extra stort eftersom läsarna ofta ser dessa som identifikationsobjekt. Clare Bradford uttrycker det så här: "When non-Indigenous authors construct Indigenous focalizers, they must imagine how these characters think, value, and feel, a highly complex task that demands a capacity to represent the other." (Bradford 2007, 73). Roderick McGillis har undersökt skillnaden mellan "knowing" i betydelsen rationell kunskap och "understanding" som ger inlevelse i en annan kultur (McGillis 2000, 223). Det senare är inte alltid lätt att åstadkomma och därför är det oftast författare med stark bindning till den kultur de vill skildra, som lyckas bäst. Som exempel på "knowing" anför McGillis boken False face av Welwyn Wilton Katz. (Boken finns i svensk översättning med titeln Det falska ansiktet). I ett efterord skriver Katz att hon har försökt vara noggrann när det gäller irokesiska sånger och ritualer kring maskerna. McGillis visar emellertid att Katz använder sitt källmaterial på ett felaktigt sätt. I spänningsskapande syfte tilldelar hon maskerna ondskefull makt, den som hittar masken blir dess ägare och har därmed kontroll över den. Problemet är att läsarna inges en illusion av autenticitet, som får dem att uppfatta irokesernas kultur som mystisk och skrämmande. De kulturella skillnaderna förklaras inte, utan assimileras till något handfast, som man bör ta avstånd ifrån. Författaren intar en dominerande position utanför kulturen (knowing) och upprepar därmed den koloniala situationen.

Med boken The birchbark house av Louise Erdrich vill jag som jämförelse ge ett exempel på "understanding". Författaren visar hur indianer av hennes egen stam (Ojibwa) levde vid mitten av 1800-talet. Genom flickan Omakayas ögon får vi följa årets gång med arbete, fest och lek. Det går att urskilja flera av de postkoloniala kriterierna i 
texten. Erdrich är t ex noga med att ange platsen där Omakayas lever: "All winter long Omakayas's family lived in a cabin of sweet-scented cedar at the edge of LaPointe, on an island in Lake Superior that her people called Moningwanaykaning, Island of the Golden-Breasted Woodpecker." (6). Författaren anger också att Omakayas är Anishinabeg, det ursprungliga namnet för indianstammarna Ojibwa eller Chippewa. Som en protest mot det engelska språket, som tvingades på indianerna, använder författaren många ord på ojibwa. Boken är försedd med en ordlista där dessa ord förklaras. Ibland är de också förklarade i den löpande texten: "Ahneen, my auntie, she said. Mino aya sana. She wished the old woman good health, and called her 'Auntie' because it was a sign of affection," (22). Även indiansk kultur och sedvänjor beskrivs ingående. Som exempel kan nämnas namngivningen. Omakayas lillebror är redan flera månader gammal, men har ännu inget namn. Endast några få människor på ön har förmåga att genom sina drömmar ta reda på vilket namn andarna vill att barnet ska ha. Återgivandet av myter och sagor är ett sätt att stärka inlevelsen i texten samtidigt som det visar författarens särart. I The birchbark house lyssnar Omakayas med stort intresse på berättelser om alltings tillkomst och om folkets historia, något som stärker känslan av gemenskap och närhet till de andra stammedlemmarna. Tiden och platsen för berättandet är viktig. Vissa sagor passar bäst på vintern kring elden, medan andra bör förmedlas utomhus till exempel när man skördar vildriset. Relationen till de vita är ansträngd och blir ännu mer negativ efter den smittkoppsepidemi som härjar bland indianerna och som leder till att det minsta barnet dör. Sorgen över brodern ger Omakayas liv en ny och allvarligare inriktning. Erdrichs närhet till den indianska kulturen gör texten både verklighetstrogen och full av inlevelse. Frågan är då om en svensk författare utan indiansk bakgrund kan ge samma känsla av autenticitet?

\section{Från äventyr till realism}

I Sverige var utgivningen av äventyrsböcker om indianer omfattande under 1900-talets första hälft (Mählqvist 1977). På 1960-talet medförde det ökade kravet på realism i barnböckerna att innehållet förändrades. Från ett mer eller mindre fritt fabulerande började nu ungdomsboksförfattarna bygga sina berättelser på insamlade fakta. Av de svenska författarna var det främst Helmer Linderholm (19161982) och Stig Ericson (1929-1986) som hörsammade de nya idéerna. Linderholm skrev bland annat en serie i nio delar om den svenskättade pojken Amisko som vid 1700-talets början togs om hand av lenape-indianer och sedan levde som indian under större delen av sitt liv. 
Böckerna ger en detaljerad skildring av indianskt liv och kultur. Bilden av indianerna är mycket positiv, för att inte säga idealiserande.

Stig Ericson påverkades starkt av 1960-talets krav på verklighetsförankrade texter och insåg snart att den information han fann i litteraturen inte var nog, utan att det också krävdes egen research. Detta resulterade i en lång rad resor till USA, besök på indianreservat och intervjuer med indianer i olika åldrar. Till skillnad från Helmer Linderholm var Stig Ericson mer intresserad av indianernas plats i den amerikanska hierarkin än av praktiska detaljer. Han var väl medveten om svårigheterna för honom som svensk att sätta sig in i indianskt tänkesätt. I förordet till Den röda vägen skriver han: "Att se och höra är naturligtvis inte detsamma som att uppleva. Skillnaden mellan att se en soldans mellan präriekullarna någonstans utanför byn Kyle och att själv deltaga i den är ofattbart stor. Starkt medveten om detta har jag i alla fall försökt beskriva en verklighet och en situation som är aktuell för många - inta bara i Syddakota." (Ericson 1977, 6).

\section{Lilla Vargen och de vitas kultur}

De fem böckerna om Lilla Vargen skrevs under åren 1980 till 1985. Eftersom konfrontationen med de vita är tydligast i den avslutande delen Lilla Vargen och de Talande Tecknen väljer jag den för närläsning. Här utgår jag från de postkoloniala kriterierna plats, språk, identitet och kultur samt relation till kolonisatörerna. Västerländska barnböcker är ofta skrivna utifrån konceptet hemma-borta-hemma, där återvändandet markerar hemmet som en fast och trygg plats. I kontrast till detta kan hemmet för $\mathrm{t}$ ex ett nomadfolk vara den plats de befinner sig på just då. Lilla Vargens folk har fråntagits sina gamla jaktmarker och tvingats bosätta sig i reservat. I bokens början får vi veta att Lilla Vargen vantrivs med att bo på samma plats. "Han längtade efter att komma bort från detta område, som de vita kalllade Reservat." (5). Tidigare hade hövdingen Svarta Örnen fört sitt folk dit där det fanns bäst tillgång på mat och villebråd. Den stora slätten som begränsades av höga berg var deras område. När solen försvann i väster sade man att den gick till vila "bortom världens yttersta kant" (31). Förr brukade man härda sin kropp genom iskalla bad och annan träning för att klara de påfrestningar som jakten innebar. Nu fanns det ingen anledning till det. "Här på Reservatet hade man slutat med detta. Jaktens och kampens tid var förbi, kanske för alltid. Varför skulle man härda sin kropp? Man hade ju ingenting att göra - utom att hämta sin magra tilldelning av mat vid Agenturen." (42). 
Som jag visade i exemplet med Louise Erdrichs bok återger många postkoloniala författare delar av sitt ursprungliga språk i sina texter. Läsare för vilka kulturen är obekant får då en inblick i språkets utseende, medan redan invigda läsare får en positiv upplevelse av igenkännande. Stig Ericson försöker framkalla indiansk mentalitet genom att översätta indianska uttryck. När Lilla Vargens fosterfar Två Fjädrar följer spåren av en stor varg drabbas han av ett häftigt snöoväder. "Detta hände i Den Stora Köldens månad, och Köld-göraren hade plötsligt kommit ridande på sin vita häst." (14). Tid och ålder anges ofta med anknytning till naturen och årstiderna: "det gröna gräsets månad" (5) "Detta är din tionde vinter" (18). Även beskrivningar av olika slag har naturen som jämförelsematerial: "Håret kring munnen och öronen liknade det döda gräset under snön." (61).

Språket och den därmed sammanhängande identiteten är viktiga kriterier i de postkoloniala texterna. Förbjudande av inhemska språk var ett av instrumenten i det koloniala förtrycket. Hövdingen för Lilla Vargens folk inser att de unga inte har något annat val än att lära sig de vitas språk. "- All de vitas Kunskap finns i deras Talande Tecken, sa Svarta Örnen" (37). Tillsammans med sin vän Rävöra skickas Lilla Vargen till de vitas skola. När läraren skriver bokstäver på tavlan tror Lilla Vargen att de ska ge ljud ifrån sig. Han förstår inte att det är han som ska göra ljuden och frustrationen blir stor när han inser att de egentligen inte betyder någonting. När Svartkappan frågar efter pojkarnas namn skakas deras identitet i sina grundvalar. "Lilla Vargens och Rävöras namn var en del av dem själva. I namnet Lilla Vargen fanns berättelsen om den döda kvinnan i snön. Där fanns spåren av den stora, mörka vargen med lysande ögon. Där fanns Vargens Ande, hans viktigaste Hjälpare... Att säga sitt namn var att lämna ut någonting av stort värde. Det gjorde man bara till människor som stod en mycket nära." (79). När läraren inte får något svar tilldelas Lilla Vargen och hans kamrat de bibliska namnen Samuel och Thomas. För indianpojkarna är det bara obegripliga ljud. Lilla Vargen förstår inte hur någon okänd kan ge honom ett namn. "Svartkappan visste ingenting om honom - inte vem han var, inte hur han var, inte vad han upplevt eller drömt..." ([80]).

Det är inte bara språket som är annorlunda när Lilla Vargen och Rävöra kommer till skolan. De andra indianbarnen har klippt håret och är klädda som amerikaner. De har börjat lära sig de vitas språk och tänkesätt och gör narr av nykomlingarna. "När Lilla Vargen gick fram mot Svartkappan, kände han hur de osynliga pilarna från barnen trängde in i hans bröst. De fick hans hjärta att krympa - och för ett kort ögonblick önskade han sig kort hår och kläder av det som kall- 
las tyg." (54). Lilla Vargen är uppvuxen i en kultur som hyllar frihet och glädje och som tar sig uttryck i sång, dans och berättande. Han tänker på trummans dunkande slag som uppmanar till rörelse. I de vitas skola står barnen stilla när de sjunger. "De vitas sång var utan liv och hjärta - liksom mycket annat i detta skrämmande hus." (51).

När det gäller relationen till kolonisatörerna visar Stig Ericson att Lilla Vargen och de andra indianbarnen är utsatta för förtryck både i sin egenskap av att vara barn och av att vara icke-vita. Först trängde de europeiska kolonisatörerna undan indianerna och därefter tvingade den amerikanska staten dem att bosätta sig i reservat och omskolas till amerikanska medborgare. Lilla Vargen är mycket rädd för att börja i de vitas skola. På frågan varför just han måste lära sig det nya språket svarar hans fosterfar: "Tänk på vem du är, sa Två Fjädrar. Tänk på ditt namn. De andra lägren har funnits här mycket längre än vårt. Någon härifrån måste bli den första. Tänk också på vad jag har sagt många gånger: att de vitas ord kan nå längre än en jägares pil." (19). När Lilla Vargen senare betraktar läraren, undrar han, vad det är för speciellt med dessa vita människor. "Lilla Vargen kunde inte förstå att just dessa vita människor hade större makt än alla andra. Men han hade hört att det var så." (61).

Genom hela boken Lilla Vargen och de Talande Tecknen ljuder en ton av sorg och förlust, konkretiserad av ordet "mörk". Redan första meningen lyder: "Det var en mörk kväll i den första vinter-månaden." (5). I beskrivningen av landskapet återkommer ständigt det mörka i form av svart vatten, mörka döda träd och mörka stenar i snön. När Lilla Vargen är på besök i skolan berättar en av de andra indianpojkarna att deras lärare hotar dem med "Det Mörka". Pojken vill inte tala om vad detta innebär och hotet om "Det Mörka" finns ständigt i Lilla Vargens tankar. Slutligen får Lilla Vargen förklaringen: "Han därinne [Svartkappan] säger att vårt folk levt i mörker till de vita kom. /---/ Han säger också att det finns en Mörk Eld långt nere under marken. Detta hotar han oss med. Han säger att vi ska brinna där längre än någon kan förstå, om vi inte lär oss tala med den han kallar Gud." (87). Men Rävöra vet att han och Lilla Vargen har en annan tro: "Vårt folk är Solens folk, sa Rävöra" (87). Den indianska religionen framställs sålunda som positiv i relation till kristendomens helveteslära.

Frågan är då om Stig Ericson lyckats med att skildra den indianska kulturen från ett postkolonialt perspektiv. Hans research bygger både på egna upplevelser och inläst material. I en artikel med titeln "Vi måste göra motstånd" berättar Stig Ericson om ett besök i Blackfeet Indian Reservation där han samlar material till böckerna om 

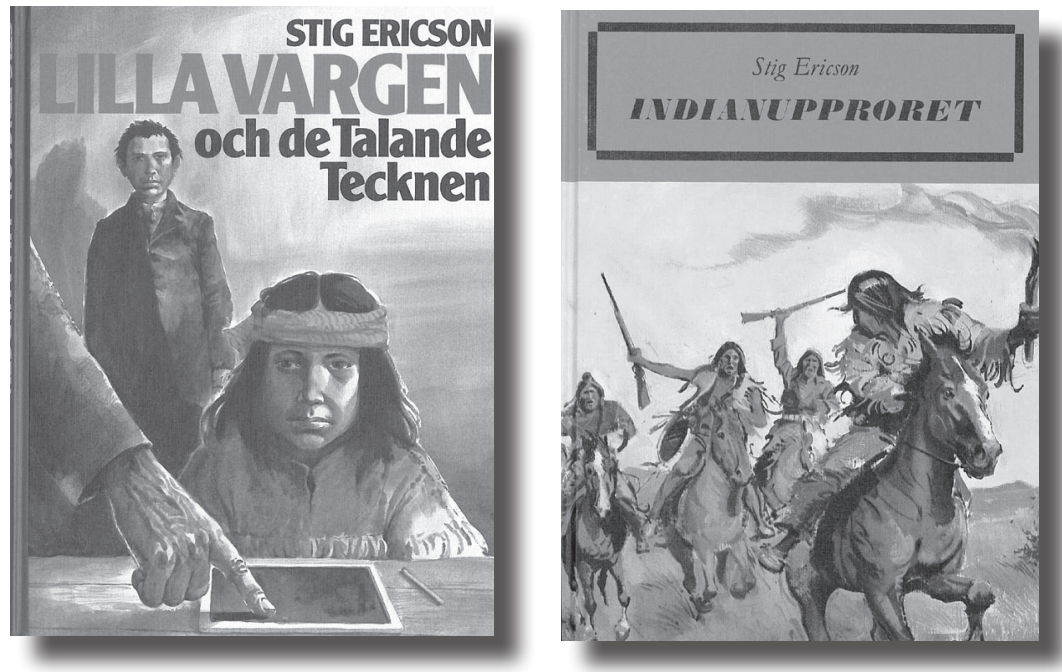

III. Tord Nygren ur Lilla Vargen...,Två Skrivare Bokförlag AB, 1985 och Nils Stödberg ur Indianupproret, Albert Bonniers förlag, 1963.

Lilla Vargen (Ericson 1984). Legenden om vargen som visade vägen till spädbarnet i snön har Stig Ericson, enligt en uppgift i Lilla Vargen får sitt namn, hämtat från en indiansk självbiografi av svartfotshövdingen Chief Buffalo Child Long Lance. Stig Ericson visar respekt och vördnad för den indianska kulturen. Bilden av indianerna kan stundtals bli idealiserande men inte romantisk. Istället för att nostalgiskt betrakta indianerna som ett utdöende minoritetsfolk manar Stig Ericson till förståelse och upprättelse för ett folk som fortfarande kämpar för sina rättigheter. Lilla Vargen och de Talande Tecknen är skriven med återhållen vrede och stor indignation över indianernas situation. Det är därför rimligt att hävda att han utgår från ett perspektiv av "understanding". Slutet är positivt och visar på det hopp om återerövring av kultur och identitet som postkoloniala texter ofta ger uttryck för: "Och vad Svartkappan än kallade honom skulle han fortsätta att vara Lilla Vargen." ([93]).

Är det då något som saknas eller något som stör det koloniala perspektivet i Stig Ericsons text? Med tanke på den känsla för nationell tillhörighet som ofta är förknippat med postkolonialt tankesätt borde det ha framgått i texten till vilket folkslag Lilla Vargen hör. $\mathrm{Nu}$ talas det enbart om "Svarta Örnens folk". De indianska namnen och benämningar av olika företeelser har ingen förankring i ett verkligt indianspråk. En hastig jämförelse med Louise Erdrichs bok The birchbark house visar skillnaden. Erdrich förlägger sin berättelse till en namngiven plats och beskriver ingående den indianstam som skildras. Det frekventa användandet av ord på ojibwa och återgivandet av myter och sägner ger Erdrichs text en stark förankring $i$ 
den indianska kulturen. Även om Stig Ericson förmår inta ett postkolonialt perspektiv förblir han en utomstående betraktare. Louise Erdrich å sin sida har ett insidesperspektiv och kan beskriva hur det känns att timme efter timme hålla på att skrapa ren en älghud eller lyckan över att få nya pärlbroderade mockasiner. I Lilla Vargen och de Talande Tecknen är det enbart pojkar som väljs ut till de vitas skola, överhuvudtaget spelar flickorna en liten roll i Stig Ericsons text. För Louise Erdrich innebär det kvinnliga perspektivet att hon skriver ur en underlägsen position, vilket kan ge större inlevelse i den förtryckta mentaliteten. Genom att dessutom ha en flicka som huvudperson lägger hon tonvikten vid de kvinnliga sysslorna och underifrånperspektivet stärks ytterligare.

\section{Petter och indianerna}

För att få en inblick i tillämpningen av den postkoloniala kritiken vill jag här gå tillbaka till Stig Ericsons tidiga indianböcker. Under 1960-talets första år började Stig Ericson nyöversätta och bearbeta indianböcker från 1800-talet. Han hade börjat tjänstgöra som lärare och när han såg att eleverna fortfarande läste böcker av bland annat James Fenimore Cooper och Edward S. Ellis kände Stig Ericson ett behov av att nyansera de värsta fördomarna. Hans första egna skönlitterära berättelser har dock stora likheter med dessa böcker. Som exempel kan nämnas Indianupproret från 1963. För att undersöka vilken syn på den indianska kulturen som texten förmedlar använder jag mig här av den postkoloniala kritikens kriterier plats, historia, språk och identitet. Boken utspelar sig i ett svenskt nybyggarområde som kallas Birch Lake och ligger i Minnesota. Familjen Lindeberg från Småland kom med ett emigrantskepp över Atlanten till Amerika sex år tidigare. När boken börjar har de odlat sin egen jord i tre år och byggt hus och ladugård. Barnen Anna och Petter kommer väl överens med siouxbarnen från indianbyn på andra sidan sjön. Barnens farbror har varit i Amerika över tjugo år och är amerikansk medborgare. Det var han som fick sin bror att ta med sig familjen och komma till det nya landet.

Indianupproret bygger på verkliga händelser, vilka är beskrivna i ett efterord. 1862 genomförde siouxindianerna ett omfattande hungeruppror i Minnesota. Indianerna var dubbelt förtryckta, dels av den amerikanska regeringen och dels av nybyggarnas krav på nya områden att odla upp. Eftersom nybyggarna befann sig i indianernas närhet drabbades de först av urinvånarnas vrede. Stig Ericson skildrar i Indianupproret hur familjen Lindeberg tvingas på flykt efter att granngårdarna bränts ner. Det är med stor bitterhet de lämnar sina hus och odlingar, som de slitit så för att sätta i stånd. Nybyg- 
garna tycker att de behandlat indianerna väl och förstår inte varför indianerna blivit så aggressiva. Däremot är de svenska nybyggarna medvetna om den amerikanska regeringens förtryck av indianerna: "De röda är ett vilt folk, sa farbror Charles. Men att de gör så här är regeringens fel. Regeringen har stängt in dem på ett litet reservat på ena sidan Minnesotafloden och ger dem varken mat eller kläder så det räcker." (65). I slutet av boken har emellertid upproret slagits ned. Indianerna kan inte stå emot de vitas överlägsna militära styrka. De blir inringade, tas till fånga och förvisas till nya reservat i Nebraska och Dakota. När familjen Lindeberg återvänder till sitt nybygge konstaterar de med glädje att deras hus är oskadda och de kan återigen ta sitt område i besittning.

Som tidigare nämnts är språk och identitet de postkoloniala kriterier som har störst betydelse när det gäller att påvisa förtryckets natur. De gånger indianerna får komma till tals sker det alltid på bruten engelska. "Varit i många hus. Inte fått mat någonstans. Blekansikten bett oss äta gräs. Blekansikten - inte bröder." (43). Ett sätt att tala som för tankarna till okunniga barn. När de anfaller de amerikanska soldaterna utstöter de "ett mångstrupigt dallrande stridsrop" (100). Då är det bilden av indianerna som krigiska vildar som frammanas. Vid ett tillfälle hör dock Petter en indian tala sitt eget språk: "Petter förstod plötsligt att indianens språk var ovanligt uttrycksfullt, och han kände en viss motvillig respekt för indianen som behärskade detta främmande tungomål." (44). För ett ögonblick framskymtar en tanke om att det kan finnas något positivt $\mathrm{i}$ indianernas kultur, men någon ytterligare reflexion över detta kommer aldrig till stånd.

Indianerna skildras ofta som exotiska och främmande. En av de indianer som kommer till gården och ber om mat beskrivs på följande sätt: "Hans långa hår stötte i grått, hans ansikte var fårat av ålder och umbäranden, och han var nästan sjukligt mager. Han hade en fjäderprydd tomahawk innanför ett färggrant bälte och två slokande svartvita örnfjädrar i håret." (45). Petter blir rädd för indianernas "mörka stickande ögon" (47) och när han kommer nära en indian känner Petter "en frän obehaglig lukt" (85). Ju längre indianernas härjningar varar desto vildare beskrivs de. "Det var en hel hord tjutande indianer som kom utspringande ur skogen - det såg ut att vara minst femtio stycken. När de jagade fram genom gräset syntes endast deras svarta hår och krigsmålade ansikten." (101). De ständiga anspelningarna på indianernas hudfärg upprätthåller fördomarna om indianerna som lägre stående varelser. I början av boken blir Petter sur på sin indianske lekkamrat och jämför hans hudfärg med en sönderrostad hink. "Lika rödbruna bägge två, tänkte han [Petter] bittert /---/. Precis 
samma färg. Enda skillnaden är att hinken är mattare." (7).

Genom närläsning av Indianupproret med utgångspunkt i de postkoloniala kriterierna tydliggörs textens kolonistiska ursprung. Innehållet präglas av synen att den västerländska rasen och kulturen är överlägsen den indianska. Nybyggarna skildras som aningslösa, utan medvetenhet om sin egen roll som kolonisatörer.

En jämförelse mellan Stig Ericsons båda verk visar en tydlig skillnad mellan Indianupproret, skriven 1963 och den drygt två decennier senare skrivna Lilla Vargen och de Talande Tecknen. Författarens kunskap och engagemang när det gäller indianernas historia och levnadsvillkor har resulterat $i$ att den senare boken med sina tydliga postkoloniala drag ger en avsevärt mer nyanserad bild av de nordamerikanska indianerna. Utifrån detta går det att konstatera att det skett en utveckling både av Stig Ericsons eget författarskap och den svenska indianboken i stort.

\section{Bibliografi}

Ashcroft, Bill, Griffiths, Gareth \& Tiffin, Helen. The empire writes back: theory and practice in post-colonial literatures. 2 uppl. London: Routledge, 2002.

Bradford, Clare. Unsettling narratives: postcolonial readings of children's literature. [Waterloo, Ont.]: Wilfrid Laurier University Press, 2007.

Burnett, Frances Hodgson. A little princess, being the whole story of Sara Crewe now told for the first time. London: Warne, 1905.

Erdrich, Louise. The birchbark house. New York: HyperionBooks for Children, 1999.

Ericson, Stig. Indianupproret. Stockholm: Bonniers, 1963.

Ericson, Stig. Den röda vägen. Stockholm: Bonnier, 1977.

Ericson, Stig. Lilla Vargen får sitt namn. Stockholm: Bonnier, 1980.

Ericson, Stig. "Vi måste göra motstånd". Abrakadabra (1984) 1: 12-13.

Ericson, Stig. Lilla Vargen och de Talande Tecknen. Stockholm: Två Skrivare Bokförlag AB, 1985.

Holmbom, Annika. "I didn't even know what an Indian was": resisting aboriginal stereotypes in children's picture books. [Åbo]: [Åbo Akademi], 2003.

Katz, Welwyn Wilton. False face. Vancouver: Douglas \& McIntyre, 1987.

Katz, Welwyn Wilton. Det falska ansiktet. Övers. Anna Iweborg. Stockholm: Rabén \& Sjögren, 1988.

Linderholm, Helmer. Fredsstigens röda: första delen av berättelsen om den svenske indianen Amisko (Lars Bure). Stockholm: Tiden, 1972.

Long, Sylvester Clark. Long Lance, by Chief Buffalo Child Long Lance, for- 
ward by Irvin S. Cobb. New York, Cosmopolitan book corporation, 1928.

Long, Sylvester Clark. Långa Lansen: en svartfothövdings självbiografi / av hövdingen buffelbarnet Långa Lansen; med förord av Irvin S. Cobb; till svenska av Brita Hebbe. Stockholm: Geber, 1929.

McGillis, Roderick. "Postcolonialism, children, and their literature". Ariel 28 (1997) 1: 7-15.

McGillis, Roderick. "And the celt knew the indian": knowingness, postcolonialism, children's literature. In Voices of the other: children's literature and the postcolonial lcontext edited by Roderick McGillis. New York: Garland, 2000, pp. 223-235.

Molin, Paulette Fairbanks. American indian themes in young adult literature. Lanham: Scarecrow Press, 2005.

Nodelman, Perry. "The other: orientalism, colonialism, and children's literature". Children's literature association quarterly 17 (1992): 29-35.

Reimer, Mavis. "Making princesses, re-making A little princess". In Voices of the other: children's literature and the postcolonial context edited by Roderick McGillis. New York: Garland, 2000, pp. 111-134.

Said, Edward W. Culture \& imperialism. London: Vintage, 1994.

Through indian eyes: the native experience in books for children edited by Beverly Slapin and Doris Seale. Los Angeles: CA Oyate, 2003.

Nyckelord: postkolonialism, makt (i litteraturen), indianböcker 